\title{
IDADE DO MAGMATISMO ALCALINO DE PARIQÜERA AÇU (SP)
}

\author{
DELZIO DE LIMA MACHADO JÚNIOR
}

\begin{abstract}
ALKALINE MAGMATISM AGE OF PARIOÜERA ACU MASSIF (SP, BRAZIL) This paper presents Rb-Sr isotopic data concerning the understanding of the origin, age and emplacement of the Pariquiera Açu massif, a small ocurrence $(3,5 \times 2,5 \mathrm{~km})$ of maficultramafic alkaline rocks discovered by aeromagnetic interpretation in 1979 . The massif is situated in São Paulo - southeastern Brazil - near the Jacupiranga and Juquiá alkaline complexes in the low Ribeira de Iguape river valley. $\mathrm{Rb}-\mathrm{Sr}$ data and the $\mathrm{K} / \mathrm{Ar}$ available ages in the literature of nearby complexes are discusssed. It has also shown and discussed the characteristic aeromagnetic pattern of Pariquiera Açu body and related intrusives, as well as its geology, rock types, distribution and age and its relationships to the nearby complexes.
\end{abstract}

Keywords: Alkaline rocks, Alkaline complexes, $\mathrm{Rb} / \mathrm{Sr}$ and $\mathrm{K} / \mathrm{Ar}$ geochronology, Brazilian alkaline complexes

RESUMO O presente artigo apresenta resultados de análises isotópicas Rb-Sr de interesse à compreensão da origem, época de formação e condicionamento tectônico da intrusiva de Pariqüera $A c ̧ u$, pequena exposição de rochas alcalinas situada no sudeste do Estado de São Paulo, na região do baixo vale do rio Ribeira de Iguape. São analisados e comparados os valores de idades K-Ar disponíveis na literatura para os complexos alcalinos de Juquiá e Jacupiranga, de localização próxima. São também discutidos o padrão magnético característico deste conjunto de ocorrências, aspectos geológicos interessantes sobre a distribuição e tipo de rochas constituintes, forma do corpo de Pariqüera Açu e sua relação cronológica com os demais complexos.

Palavras-chaves: Magmatismo alcalino, Geocronologia, Alinhamento de Guapiara

INTRODUÇÃo A intrusão alcalina de Pariqüera Açu é um pequeno maciço no qual expõem-se descontinuamente rochas alcalinas de natureza variada entre intermediária a máfica, contendo tipos ultramáficos. Tais rochas ocorrem na localidade de Pariqüera Mirim, sudeste de São Paulo, localizada $10 \mathrm{~km}$ a leste da cidade de Pariqüera Açu (Fig. 1).

Por aflorar em terrenos erodidos e topograficamente rebaixados, considerando-se o relevo circundante, o corpo de Pariqüera Açu acabou por ser descoberto apenas por interpretação de dados aeromagnetométricos, embora apresente boas exposições com afloramentos pouco alterados. Sua área de exposição estende-se por cerca de $3,5 \mathrm{~km}$ na direção NW e $2,5 \mathrm{~km}$ na NE, estando orientado com o trend principal do Alinhamento de Guapiara, visível pelo desenho das linhas de campo magnético na figura 2.

Trabalhos Anteriores O primeiro trabalho que sugeriu a possibilidade de uma exposição de rochas alcalinas próximo à localidade de Pariquiera Açu deve-se a Ferreira \& Algarte (1979). Nessa ocasião os autores reconheceram dois padrões magnéticos anômalos centrados respectivamente a leste das cidades de Pariqüera Açu e de Registro, a partir da análise dos mapas de contorno magnético do Projeto São Paulo-Rio de Janeiro (CPRM 1978). Tais anomalias foram então interpretadas como produto de duas fontes magnéticas tridimensionais em profundidade e, ao mesmo tempo, sugerida sua relação genética com os complexos alcalinos de Juquiá e Jacupiranga. Inicialmente supostas como duas ocorrências subaflorantes, devido ao padrão típico de anomalia magnética centrada, a de Pariqüera Açu revelou-se como um pequeno macico alcalino, formado principalmente por shonkinitos e malignitos (Ferreira et al. 1987), ao passo que a de Registro acha-se em área inteiramente tomada por sedimentos da planície aluvionar do Rio Ribeira de Iguape. Uma nota preliminar referente ao tema do presente trabalho foi divulgada por Machado Jr. (1998).

Em trabalho recente Coutinho et al. (1998) detalharam petrográfica e quimicamente a intrusão de Pariqüera $\mathrm{Açu,} \mathrm{confirmando} \mathrm{a} \mathrm{natureza}$ máfica alcalina e o predomínio de shonkinitos e malignitos, contendo ainda em menor proporção piroxenitos e nefelina sienitos. Estes autores destacam sobretudo os altos teores em potássio das rochas constituintes, ao que se deve aliar a ausência de carbonatitos, o que as diferencia dos demais complexos próximos.

AEROMAGNETOMETRIA O maciço de Pariqüera Açu, tal como os complexos alcalinos do tipo central, apresenta um padrão magnético característico, com linhas de campo magnético convergentes, que se destaca daquele padrão linear resultante da estruturação geral NW do Alinhamento de Guapiara. Os mapas de contorno magnético constituem, portanto, uma poderosa ferramenta discriminante destas estruturas, particularmente em áreas com intensa alteração supérgena, de relevo pouco pronunciado ou aquelas cobertas por sedimentação recente.

As ocorrências das anomalias de Jacupiranga, Juquiá e Registro são evidentes pelo desenho fornecido pelas curvas de isovalores do campo magnético (Fig. 2). Observando-se o padrão dos centros convergen- tes na região, nota-se a semelhança de Pariqüera Açu sobretudo com a anomalia que ocorre próximo a Registro, no que diz respeito ao tamanho e intensidade magnética. Tal anomalia deve indicar um corpo de dimensões semelhantes em profundidade não muito grande, conforme já havia sido considerado por Ferreira \& Algarte (1979).

\section{ASPECTOS GEOLÓGICOS Forma do corpo de} Pariqüera Açu O maciço alcalino de Pariqüera Açu apresenta forma alongada segundo a direção NW, de onde pode se abstrair dois eixos (Fig. 1). O maior alinha-se com a direção N5OW e se estende por cerca de $3,5 \mathrm{~km}$, enquanto o menor é ortogonal, com $2,5 \mathrm{~km}$. Sua forma de afloramento acompanha a estruturação regional, resultado da presença de fraturas e diques de diabásio, considerados como geneticamente associados ao Alinhamento de Guapiara, o que revela o mesmo condicionamento tectônico. A associação das estruturas rúpteis e diques de diabásio é responsável pelo padrão geral orientado a NW das linhas do campo magnético, conforme se observa na figura 2.

Petrografia Considerando a extensão aflorante percebe-se que $o$ maciço de Pariqüera Açu é constituído predominantemente por shonkinitos e malignitos associados, porém há uma importante presença de álcali piroxenitos e menor de nefelina sienitos, esta última reconhecida por Coutinho et al. (1998). A ocorrência dos litotipos mencionados dá-se sobretudo nos locais de relevo mais acentuado, como a sua metade norte, e a parte sul. Devido às excelentes exposições, a amostragem para análise isotópica concentrou-se na parte norte (Fig. 1).

Os piroxenitos situam-se na porção norte do corpo, aparentemente constituindo af o seu limite, enquanto os shonkinitos e malignitos distribuem-se pelo restante da área, devendo estender-se até o seu limite sul. Em sua extremidade NW ocorre ainda pequena exposição de rochas brechadas, associadas a filitos quartzosos ou milonitos encaixantes, cujo reconhecimento de campo é difícil, em virtude da forte alteração.

Os shonkinitos e malignitos de Pariqüera Açu são rochas constituídas por quantidades variáveis de clinopiroxênio (augita titanífera), olivina, biotita titanífera, apatita e eventualmente anfibólio alcalino (arfvedsonita), ocorrendo em meio a $\mathrm{K}$ feldspatos ricos em $\mathrm{Na}$ e nefelina tipicamente intersticial. Apresentam notável orientação mineral e sua textura é granular hipidiomórfica, média a grossa revelada pelos grãos de minerais máficos. Nos piroxenitos estão presentes clinopiroxênio (augita titanífera), biotita titanífera, olivina eventual e apatita. É comum um arranjo paralelo dos minerais máficos que sugere deposição cumulática. O conjunto de rochas existente é sugestivo de diferenciação a partir de um magma primitivo ultramáfico, que evoluiu fracionadamente para os termos mais félsicos.

IDADE DE PARIQÜERA AÇU Com o objetivo de determinar a idade de formação das intrusivas de Pariqüera Açu, foram obtidas no terreno exemplares inalterados de rochas representativas do maciço para análise isotópica. A boa qualidade das exposições, aliada à natureza máfico-alcalina apresentada pelas amostras, permitiu-nos a escotha de sete exemplares de shonkinitos para análise $\mathrm{Rb}-\mathrm{Sr}$. 


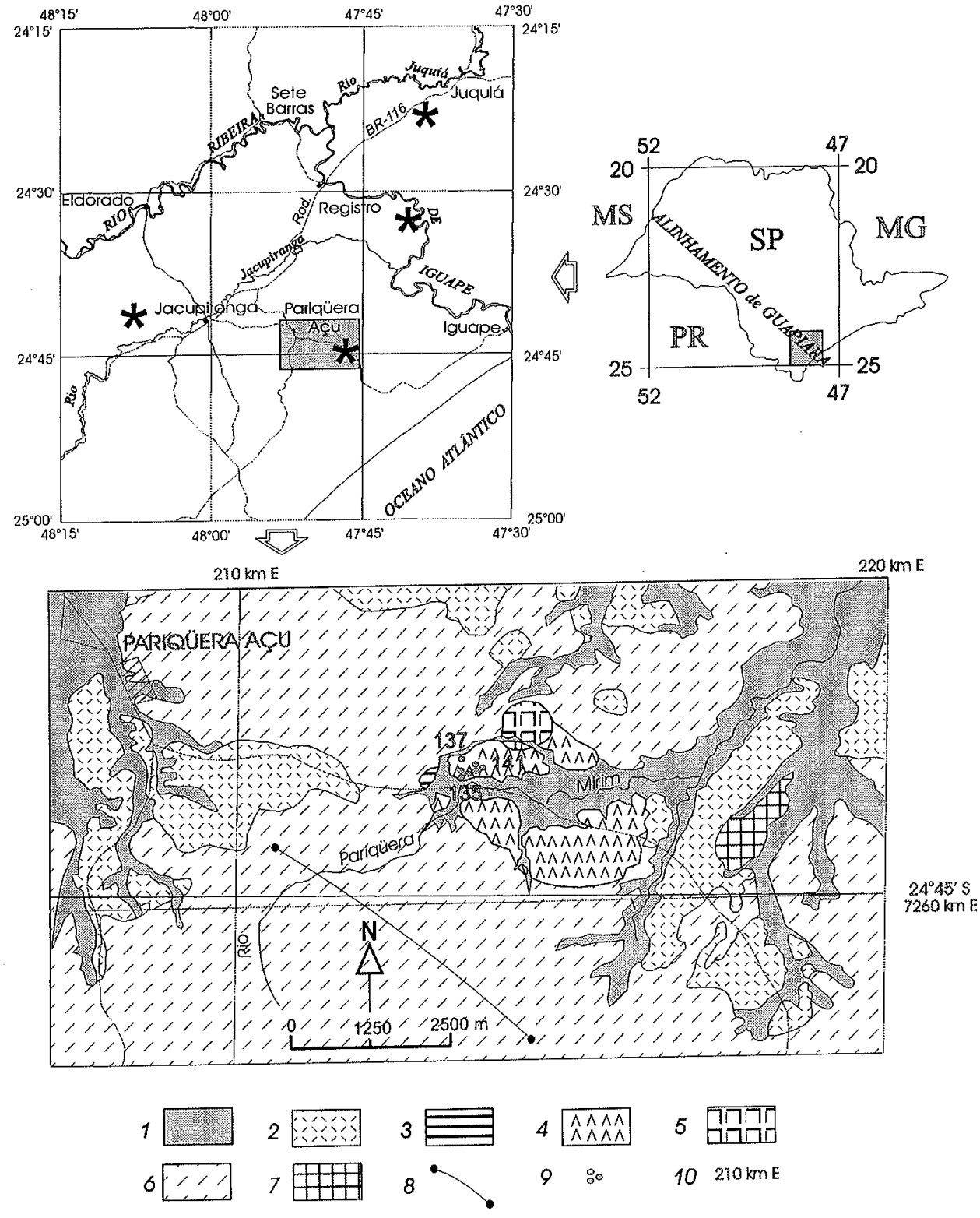

Figura 1-Localização, acessos e geologia do maciço alcalino de Pariqüera Açu. 1 - Sedimentos inconsolidados de planícies aluvionares; 2 - Sedinentos fluviais elevados em terraços; 3 - Brechas; 4 - Shonkinitos e malignitos; 5 - Piroxenitos; 6 - Micaxistos diversos; 7 - Gnaisses e migmatitos; 8 - Dique de diabásio; 9 - Ponto de amostragem para geocronologia; 10 - Coordenada UTM.

Embora os shonkinitos apresentem-se textural e mineralogicamente homogêneos, existem variações sutis na distribuição dos minerais máficos e félsicos que favoreceram a análise isotópica em rocha total para $\mathrm{Rb}$ e $\mathrm{Sr}$, conforme se verifica na Tabela 1.

Resultados $\mathbf{R b}-\mathbf{S r}$ A Tabela 1 apresenta os resultados analíticos para $\mathrm{Rb}$ e $\mathrm{Sr}$, bem como as razões isotópicas obtidas para sete amostras de shonkinitos provenientes das exposições assinaladas na Figura 1. A homogeneidade apresentada pelos exemplares escolhidos, aliada à proximidade dos pontos de coleta das amostras em afloramento, garantem sua cogeneticidade, o que pode ser atestado pelos resultados obtidos.

De acordo com a Tabela 1, as combinações dos parâmetros encontrados forneceram valores de $\mathrm{Rb}^{87} / \mathrm{Sr}^{86} \mathrm{e} \mathrm{Sr}^{87} / \mathrm{Sr}^{86}$ favoráveis à construção de uma isócrona, apresentada na figura 3 . Obteve-se um excelente alinhamento utilizando-se seis amostras, cujos pontos definiram uma reta de inclinação correspondente à idade de $142,1 \pm 7,3 \mathrm{Ma}$. A validade desta determinação pode ser estimada pelos bons níveis de correlação linear $\mathrm{R}=0,99528$ e MSWD $=0,7308$ obtidos. $\mathrm{O}$ valor encontrado para a razão inicial $\left(R_{0}=0,705203 \pm 0,00010\right)$ confirma uma derivação mantélica, sem indícios de contaminação por material crustal para a intrusão de Pariqüera Açu. Uma única amostra (ponto 2, DL$141 \mathrm{~A}$ ) não foi incluída no cálculo da isócrona. Tal amostra é muito semelhante quanto a composição mineral e petrografia a duas outras também investigadas (DL-141B e DL-141C), sendo todas obtidas essencialmente da mesma área de exposição. A julgar pelos teores de $\mathrm{Rb}$ e $\mathrm{Sr}$ obtidos para o trio analisado (Tabela 1), a razão isotópica $\mathrm{Rb}^{87}$ / $\mathrm{Sr}^{86}$ da amostra DL-141A provavelmente foi minorada por excesso de $\mathrm{Sr}$, o que comprometeu um melhor alinhamento entre os pontos $2,6 \mathrm{e}$ 7 e, de resto, entre os demais da isócrona (Fig. 3). Mesmo após reanálise, suas razões isotópicas inicialmente obtidas foram confirmadas. Por outro lado, os resultados encontrados para as demais amostras (DL-137B, DL-135A, DL-135B e DL-135C) confirmam a vinculação genética do conjunto, além de mostrar coerência entre a distribuição dos valores isotópicos. Assim, preferiu-se eliminar a amostra referente ao ponto 2 do cálculo realizado de modo a minimizar os fatores que aumentassem a incerteza e afetassem o valor da idade para o Maciço de Pariquiera Açu.

A PROVÍNCIA ALCALINA DE GUAPIARA Na região sudeste do Estado de São Paulo a atividade ígnea mesozóica está representada por inúmeros diques de diabásio, dispostos segundo feixes subparalelos às direções N40-50W e pelos complexos alcalinos eocretácicos de Jacupiranga e Juquiá, que compreendem duas associações plutônicas de rochas máficas-ultramáficas alcalinas com peridotitos, piroxenitos, ijolitos, nefelina sienitos, álcali gabros e nú- 


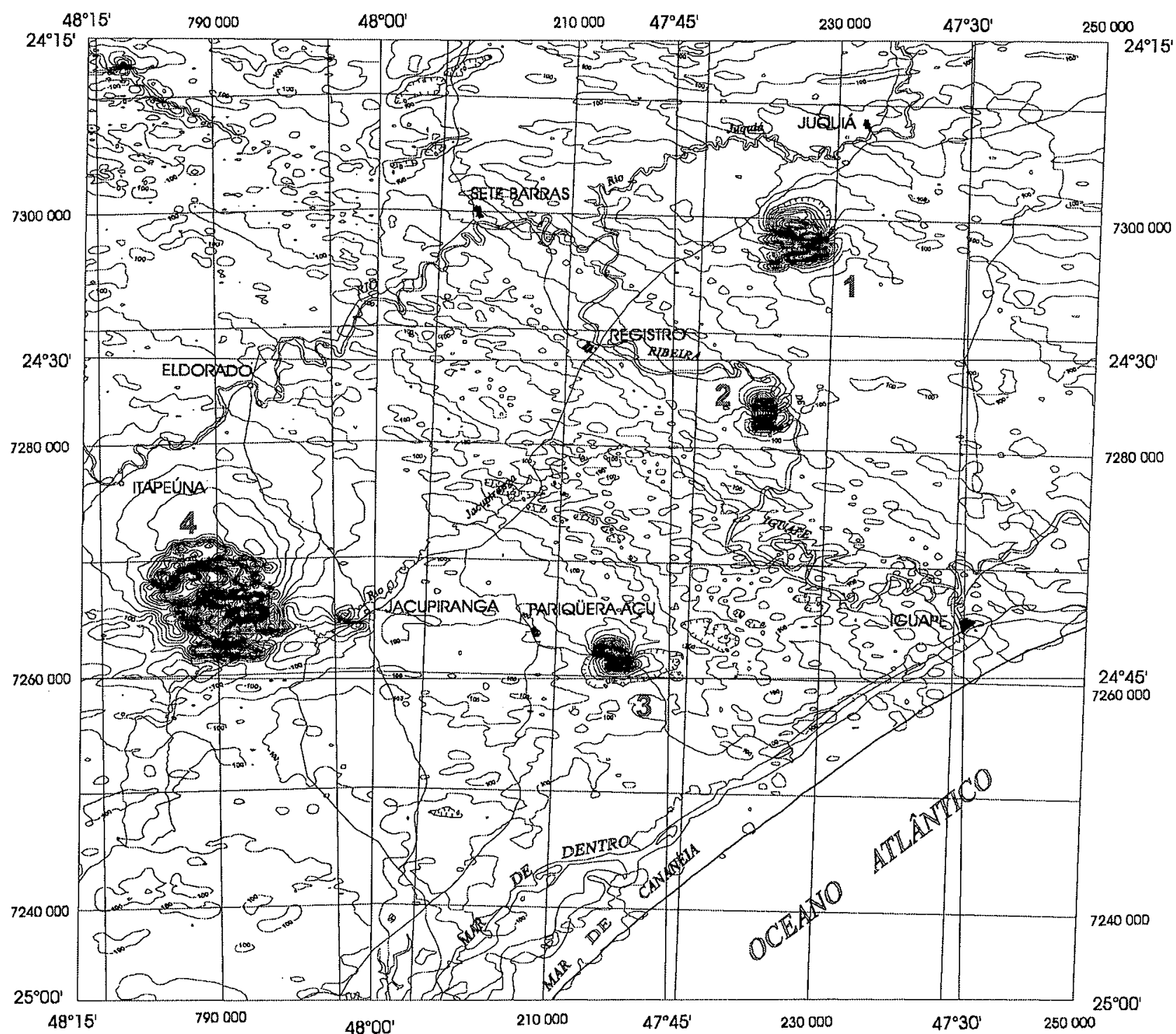

Figura 2-Mapa de anomalias magnéticas da região sudeste de São Paulo. Intervalo das linhas contorno = 100 nT. $1-$ Complexo de Juquiá, $2-$ Anomalia de Registro, 3 - Maciço de Pariqüera Açu, 4-Complexo de Jacupiranga

cleos carbonatíticos. Juntam-se a estas as notáveis anomalias magnéticas de Registro e Pariqüera Açu, reconhecidas inicialmente por Ferreira \& Algarte (1979) e Ferreira et al. (1987).

Este conjunto de centros alcalinos e diques de diabásio determina um notável padrão magnético ilustrado na figura 2 . Tal associação já havia sido relacionada por Almeida (1983) como integrante do Alinhamento Estrutural de Guapiara, sugestivo de estar condicionada a uma zona de distensão crustal orientada a NW, onde se deu a mobilização tanto de magmas alcalinos como tolé́ticos, no Cretáceo Inferior.

Ainda de destaque por sua importância petrológica, embora difíceis de serem cartografados, são os pequenos diques de lamprófiros máficos alcalinos eventualmente encontrados e vez ou outra referidos na literatura. Um discreto grupamento destes corpos acha-se descrito e pode ser reconhecido nos mapas geológicos existentes na região do médio Rio Ribeira de Iguape (IPT 1985), talvez relacionado remotamente ao magmatismo formador do complexo de Jacupiranga. Já na região do baixo Rio Ribeira também existem alguns corpos semelhantes, mas de distribuição mais rara, possivelmente contemporâneos à formação do maciço alcalino de Pariqüera Açu.

Deste modo, Pariqüera Açu figura como mais um integrante do grupo de corpos alcalinos que ocorre na região sudeste do Estado de São Paulo. De fato, encontra-se próximo aos complexos de Juquiá, 40 $\mathrm{km}$ a norte, e Jacupiranga, $35 \mathrm{~km}$ a oeste. A anomalia magnética de Registro, presente entre Juquiá e Pariqüera Açu, é altamente sugestiva da existência de outro corpo alcalino, só que totalmente encoberto por sedimentos quaternários.
Tabela I-Resultados analíticos Rb-Sr para shonkinitos de Pariquiera Açu

\begin{tabular}{|c|c|c|c|c|c|c|c|}
\hline Pontd & $\mathbf{N}^{\text {" Amostra/N }}$ Campo & $\mathbf{R b}(\mathbf{p p m})$ & $\mathbf{S r}(\mathbf{p p m})$ & \multicolumn{2}{|c|}{$\mathbf{R b}^{\mathbf{8 7}} / \mathbf{S r}^{\mathbf{8 6}}$} & \multicolumn{2}{|c|}{$\mathbf{S r}^{\mathbf{8 7}} / \mathbf{S r}^{\mathbf{8 6}}$} \\
\hline 1 & $13497 / \mathrm{DL}-137 \mathrm{~B}$ & 105,13 & 803,93 & 0,3784 & 0,0031 & 0,70600 & 0,00008 \\
\hline 2 & $13498 / \mathrm{DL}-141 \mathrm{~A}$ & 217,20 & 627,90 & 1,0010 & 0,0280 & 0,70830 & 0,00009 \\
\hline 3 & $13499 / \mathrm{DL}-135 \mathrm{~A}$ & 172,90 & 626,90 & 0,7990 & 0,0230 & 0,70685 & 0,00008 \\
\hline 4 & $13500 / \mathrm{DL}-135 \mathrm{~B}$ & 294,80 & 543,40 & 1,5700 & 0,0440 & 0,70852 & 0,00009 \\
\hline 5 & $13501 /$ DL-135C & 195,60 & 576,80 & 0,9810 & 0,0280 & 0,70711 & 0,00009 \\
\hline 6 & $13502 / \mathrm{DL}-141 \mathrm{~B}$ & 203,80 & 512,50 & 1,1510 & 0,0330 & 0,70744 & 0,00008 \\
\hline 7 & $13503 / \mathrm{DL}-141 \mathrm{C}$ & 232,80 & 541,90 & 1,2430 & 0,0350 & 0,70768 & 0,00008 \\
\hline
\end{tabular}

DISCUSSÃO No presente artigo, todos os valores de idade reportados estão de acordo com as atuais constantes de decaimento radiativo, conforme recomendação de Steiger \& Jaeger (1977), enquanto que os obtidos anteriormente foram recalculadas por Sonoki \& Garda (1988).

A primeira referência contendo dados radiométricos de interesse à área aqui enfocada deve-se a Amaral et al. (1967). Estes autores obtiveram idades $\mathrm{K}$-Ar pioneiras para os complexos ultramáfico-alcalinocarbonatíticos de Jacupiranga e Juquiá (outrora Serrote). Do Complexo de Jacupiranga foram reportados resultados de análises de minerais de cinco amostras, incluindo nefelina sienito (biotita), carbonatito (flogopita), piroxenito (feldspato) e jacupiranguitos (rocha total e piroxênio). Os valores recalculados são: $134,1 \pm 4,6 ; 135,9 \pm 6,8$; $137,3 \pm 5,2 ; 139,7 \pm 7,1$ e 191,6 $\pm 14,6 \mathrm{Ma}$. Para o Complexo de Juquiá foram analisados nefelina sienito (rocha total) e sienitos (biotita e feldspato), cujos respectivos resultados são: $132,6 \pm 4,2 ; 148,2$ e $162,6 \pm 4,7 \mathrm{Ma}$ (Sonoki \& Garda 1988). 


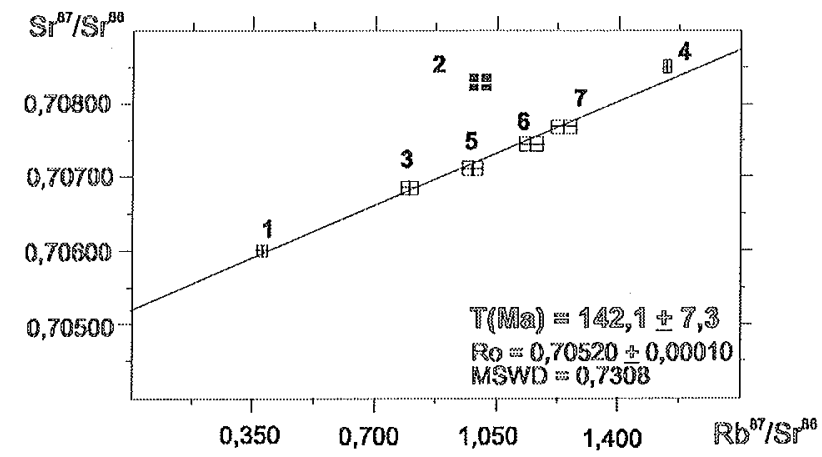

Figura 3 - Diagrama isocrônico de shonkinitos de Pariqüera Açı

Outros valores de idades K-Ar foram citados para o Complexo de Juquiá por Born et al. (1972). Tais autores discutem resultados preliminares obtidos a partir de sienitos e biotitas, reconhecendo a existência de dois conjuntos discrepantes de idades, um eocretácico e outro mais antigo. Sonoki \& Garda (1988) fornecem resultados analíticos KAr para este complexo pelos quais se percebe uma significativa dispersão de valores, contudo observando-se também idades eocretácicas.

Amaral (1978) também apresentou novos resultados K-Ar para Jacupiranga, elevando para quarenta e cinco o total de determinações conhecidas para este complexo. A figura 4 apresenta um diagrama sintético que ilustra a distribuição preferencial de idades K-Ar existente até o presente para os dois complexos.

Por sua vez, Roden et al. (1985) apresentam uma isócrona mineral $\mathrm{Rb}-\mathrm{Sr}$ para o carbonatito de Jacupiranga, que forneceu idade de $131 \pm$ $3 \mathrm{Ma}\left(\mathrm{R}_{0}=0,70501 \pm 0,00006\right)$, muito próximo dos valores $\mathrm{K}$-Ar mais freqüentes obtidos para este complexo.

Já Ferreira et al. (1987) apresentaram uma única determinação KAr em rocha total para a intrusão alcalina de Pariquiera Açu, cuja cifra de $200 \pm 3 \mathrm{Ma}$ é demasiadamente elevada e discrepante do contexto regional, se comparada aos complexos vizinhos. Tal resultado motivou a presente pesquisa.

Quando se considera o resultado aqui apresentado $(142,1 \pm 7,3 \mathrm{Ma})$ e, de modo favorável, a margem de erro envolvida, aliado à natureza magmática peculiar, conclui-se que há uma coincidência, no tempo e no espaço, entre o magmatismo de Pariqüera Açu e os complexos vizinhos. A despeito de sua natureza alcalina potássica, Pariqüera Açu é mais um dentre vários centros de manifestação alcalina neocomianos, integrando a primeira fase de ativação tectonomagmática mesozóica, ocorrida no Brasil meridional (Almeida 1971).

Em conjunto, o grupamento de centros alcalinos formado por Pariqüera Açu, Jacupiranga e Juquiá, mais a anomalia magnética de Registro, faz parte do Alinhamento de Guapiara, conforme proposto por Almeida (1983) estando, portanto, condicionados a uma zona de distensão crustal que segue na direção NW, que esteve ativa no início do Cretáceo Inferior, e cujos representantes mais expressivos são os inúmeros diques de diabásio.

Outras determinações radiométricas $\mathrm{K}-\mathrm{Ar}$ e $\mathrm{Ar}^{40}-\mathrm{Ar}^{39}$ foram obtidas mais recentemente a partir de diques de diabásio. Os valores repor-
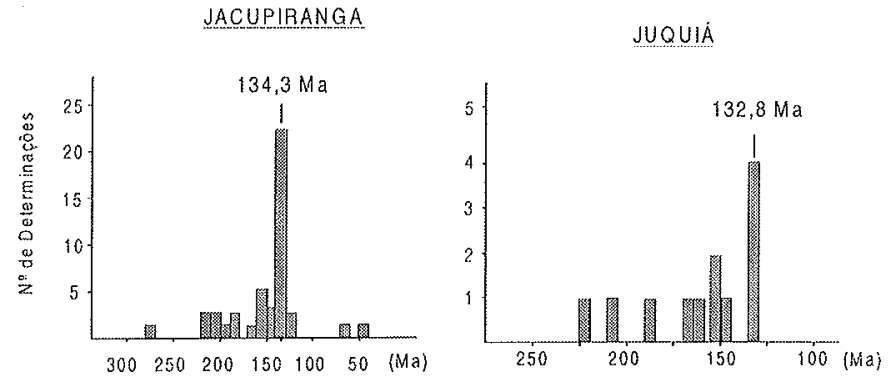

Figura 4 - Idades $K$-Ar dos complexos alcalinos de Jacupiranga e Juquiá, com média dos resultados mais frequientes (valores recalculados por Sonoki \& Garda 1988)

tados e a ligação comum com estruturas de distribuição regional, cronologicamente relacionadas, permitem a associação com o tema aqui abordado. Portanto, mesmo distantes da área aqui considerada, tais análises provém de corpos situados na extensão noroeste do mesmo sistema rúptil representado pelo Alinhamento de Guapiara.

Pinese (1989) apresenta três determinações K-Ar com amostras de diques de diabásio da região central do Alinhamento de Guapiara, em São Paulo. Tais determinações envolveram, respectivamente, uma análise em rocha total, com $125,1 \pm 5,5 \mathrm{Ma}$, e duas em plagioclásios, com $127,6 \pm 5,6$ e $143,7 \pm 6,3 \mathrm{Ma}$.

Renne et al. (1996) apresentam cinco determinações $\mathrm{Ar}^{40}-\mathrm{Ar}^{39} \mathrm{em}$ plagioclásios de diques da região de Fartura (SP). Os resultados calculados pelas técnicas de idade platô e isocrônica mostram-se perfeitamente concordantes, fornecendo $131 \mathrm{Ma}$ como valor para a idade do magmatismo dos diques toleíticos daquela região.

CONCLUSÕES O quadro geocronológico aqui apresentado confirma a existência de um importante período de atividade magmática alcalina para a região sudeste de São Paulo no Cretáceo Inferior. Esta atividade magmática concentrou-se no andar Neocomiano e esteve limitada a uma faixa rica em estruturas rúpteis que condicionou também a localização dos diques de diabásio integrantes do Alinhamento Estrutural de Guapiara. Por outro lado, considerando a extensão da região abrangida pelo alinhamento, a distinção entre os magmatitos presentes e os resultados radiométricos aqui relatados, verifica-se que as rochas alcalinas parecem ter tido sua formação ligeiramente anterior à atividade maior toleítica dos diques de diabásio. A julgar pela distribuição de idades, a atividade magmática concentrou-se entre 130 e 142 $\mathrm{Ma}$, possivelmente com as intrusivas de Pariqüera Açu precedendo suas congêneres. O elemento de relação entre elas parece ser, portanto, a natureza da ativação tectônica eocretácica no alinhamento, eminentemente distensiva, que agiu sobre descontinuidades profundas, gerando produtos magmáticos distintos.

Agradecimentos À Fundação de Amparo à Pesquisa do Estado de São Paulo - FAPESP (Processos 95/8810-1 e 99/1211-6) e ao Conselho Nacional de Desenvolvimento Científico e Tecnológico - $\mathrm{CNPq}$, a dois revisores anônimos da RBG, e entidades e pessoas que propiciaram este artigo.

\section{Referências}

Almeida F.F.M. 1971. Condicionamento tectônico do magmatismo alcalino mesozóico do Sul do Brasil e do Paraguai ocidental. An. Acad. bras. Cienc. 43:835-836.

Almeida F.F.M. 1983. Relações tectônicas das rochas alcalinas mesozóicas da região meridional da Plataforma Sul-americana. Rev. Bras. Geoc. 13:139-158.

Born H., Kawashita K., Carvalho R.M. 1972. Geocronologia do complexo alcalino de Juquíá. In: Cong. Bras. Geol., 26, Belém, 1972, Resumo da Comunicações, p.20. Amaral G., Bushee J., Cordani U.G., Kawashita K., Reynolds J.H. 1967. Potassium-argon ages of alcaline rocks from southern Brazil. Geoch. Cosmoch. Acta, Oxford, 31:117142 .

Amaral G. 1978. Potassium-argon age studies on the Jacupiranga alkaline district. State of São Paulo, Brasil. In: Simp. Intern. Carbon., 1, Poços de Caldas. Anais... Poços de Caldas, DNPM/MME, p. 207-302

Coutinho J.M.V., Valarelli J.V., Rodrigues E.P. 1998. The mafic intrusion of Pariqüera Açu, São Paulo, Brazil. An. Acad. bras. Cienc. (no prelo)

CPRM 1978. Projeto aerogeofísico São Paulo-Rio de Janeiro - Áreas III e IV. Rio de Janeiro (dados do levantamento aeromagnético).

Ferreira F.J.F. \& Algarte J.P. 1979. O comportamento aeromagnetométrico-cintilométrico das principais rochas alcalinas dos estados de São Paulo e Paraná. In: Simp. Reg. Geol,, 2, Rio Claro, 1979. Atas... Rio Claro, SBG. v.2, p. 195-208.

Ferreira F.J.F., Algarte J.P., Theodorovicz A., Monma R., Martins F.A.G., Tassinari C.C.G., Silva R.B., Rodrigues E.P., Coutinho J.M.V. 1987. A alcalina de Pariquera Açu. In: Simp. Reg. Geol., 6, Rio Claro, 1987. Atas... Rio Claro, SBG. v.2, p.159-172.
IPT 1985. Geologia das folhas de Iporanga (SG-22X-B-V-2) e Gruta do Diabo (SG-22XB-VI-1) - Estado de São Paulo. Relatório IPT Nº 22.352

Machado Jr: D.L 1998. Geocronologia Rb-Sr do macico alcalino de Pariquiera Açu-SP. In: Cong. Bras. Geol., 40, Belo Horizonte, SBG/MG. Anais..., p.466.

Pinese J.P.P. 1989. Cacterização petrológica e geoquímica dos diques do arco de Ponta Grossa. Dissertação de Mestrado - IAGUSP, $196 \mathrm{p}$

Renne P.R., Deckart K., Ernesto M., Féraud G., Piccirillo E.M. 1996. Age of the Ponta Grassa dike swarm (Brazil), and implications to Paraná flood volcanism. Earth Plantet. Sci. Lett., 144:199-211.

Roden M.F., Murthy V.R., Gaspar J.C. 1985. Sr and Nd isotopic composition of the Jacupiranga carbonalite. J. Geol. 93:212-220

Sonoki I.K. \& Garda G.M. 1988. Idades K-Ar de rochas alcalinas do Brasil meridional e Paraguai oriental: compilaçâo e adaptação às novas constantes de decaimento. $B o l$. IG.USP, Série Científica, 19:63-85.

Steiger R.H. \& Jaeger E. 1977. Subcommission on geochronology: convention on the use of the decay constants in geochronology and cosmochronology. Earth and Plantary Science Letters, 36:359-362.

Manuscrito A-1076 Recebido em 5 de março de 1999 Revisão do autor em 22 de janeiro de 2000 Revisão aceita em 25 de janciro de 2000 